\title{
DNA-based and geometric morphometric analysis to validate species designation: a case study of the subterranean rodent Ctenomys bicolor
}

\author{
J.F.B. Stolz, G.L. Gonçalves, L. Leipnitz and T.R.O. Freitas \\ Laboratório de Citogenética e Evolução, Departamento de Genética-Programa \\ de Pós-Graduação em Genética e Biologia Molecular, Instituto de Biociências, \\ Universidade Federal do Rio Grande do Sul, Porto Alegre, RS, Brasil \\ Corresponding author: T.R.O. Freitas \\ E-mail: thales.freitas@ufrgs.br
}

Genet. Mol. Res. 12 (4): 5023-5037 (2013)

Received October 9, 2012

Accepted March 5, 2013

Published October 25, 2013

DOI http://dx.doi.org/10.4238/2013.October.25.1

\begin{abstract}
The genus Ctenomys (Rodentia: Ctenomyidae) shows several taxonomic inconsistencies. In this study, we used an integrative approach including DNA sequences, karyotypes, and geometric morphometrics to evaluate the taxonomic validity of a nominal species, Ctenomys bicolor, which was described based on only one specimen in 1912 by Miranda Ribeiro, and since then neglected. We sampled near the type locality assigned to this species and collected 10 specimens. A total of 820 base pairs of the cytochrome $b$ gene were sequenced and analyzed together with nine other species and four morphotypes obtained from GenBank. Bayesian analyses showed that $C$. bicolor is monophyletic and related to the Bolivian-Matogrossense group, a clade that originated about 3 mya. We compared the cranial shape through morphometric geometrics of $C$. bicolor, including the specimen originally sampled in 1912, with other species representative of the same phylogenetic group (C. boliviensis and C. steinbachi). C. bicolor shows unique skull traits that distinguish it from all other currently known taxa. Our findings confirm that the specimen collected by
\end{abstract}


Miranda Ribeiro is a valid species, and improve the knowledge about Ctenomys in the Amazon region.

Key words: Ctenomyidae; Cytochrome $b$; Evolution; Molecular phylogeny

\section{INTRODUCTION}

Inferences regarding evolutionary diversification and speciation processes or biogeographic patterns rely on accurate knowledge of species, and therefore unambiguous taxa designation is critical. During the past 50 years, rodent species were delimited based only on morphological characters, such as cranial and tooth shapes, body size, and pelage coloration. However, current studies are showing that these traits alone, or based on a few specimens (sometimes only one), often fail to delineate taxa within a given taxonomic group (Ross et al., 2010). A remarkable example is the subterranean rodents of the genus Ctenomys (Rodentia: Ctenomyidae), commonly known as tuco-tucos, a highly diverse group with a recent adaptive radiation in the Neotropics (Cook and Lessa, 1998; Lessa and Cook, 1998). The genus includes 60 recognized species and several groups of morphotypes with uncertain taxonomic position (Woods and Kilpatrick, 2005). In general, species grouped within this genus were described based on biogeography, morphology, and karyotype (Reig et al., 1990). Recently, efforts have been made to resolve the phylogenetic relationships among groups using mitochondrial cytochrome $b$ (cyt- $b$ ) and nuclear intron sequences, but uncertainties still remain (Parada et al., 2011). In addition, some species show inconsistency in relation to taxa designation, in part due to a lack of knowledge and available material, and also because characters used to describe them (e.g., diploid number in the complex Ctenomys perrensis species group) often overlap.

In this study, we focused on Ctenomys bicolor, a nominal species with uncertain taxonomic position and endemic to northwestern Brazil, specifically on the border of the Amazon ecoregion. The type specimen was collected in 1912 by the zoologist Alipio Miranda Ribeiro during the Roosevelt-Rondon Scientific Expedition (Avila-Pires, 1968) in remote areas of the Brazilian Amazon basin. It was described based on the external morphology of a single holotype individual, which is deposited in the National Museum of Rio de Janeiro (Museu Nacional do Rio de Janeiro; MNRJ-2052) (Langguth et al., 1997). The description of this individual (of unknown sex) was published two years later (Miranda Ribeiro, 1914), with no mention of the type locality, which was later indicated as the State of Mato Grosso (Miranda Ribeiro, 1955; Avila-Pires, 1968). In a recent historical review, Bidau and Avila-Pires (2009) redefined the type locality as a location in the current State of Rondônia (Figure 1). Interestingly, after the Roosevelt-Rondon expedition, no specimens were collected in northwestern Brazil, with the exception of one collected by Allen (1916), raising doubts about the taxonomy of C. bicolor and its phylogenetic position, and suggesting that it may have become extinct during the last 100 years.

Recently, as part of a long-term project to study the taxonomy of forest species of Ctenomys, we collected specimens in a locality close to the original site described by Miranda Ribeiro, thus making it possible to rediscover $C$. bicolor and test whether it is a valid species. The lack of knowledge about species of tuco-tucos inhabiting this part of Brazil is evident, as their distribution, taxonomy, and systematics are poorly described. Therefore, a taxonomic revision of these species is essential to provide a solid basis for future studies on ecology and conservation, particularly because they inhabit a landscape that is undergoing dramatic changes. 


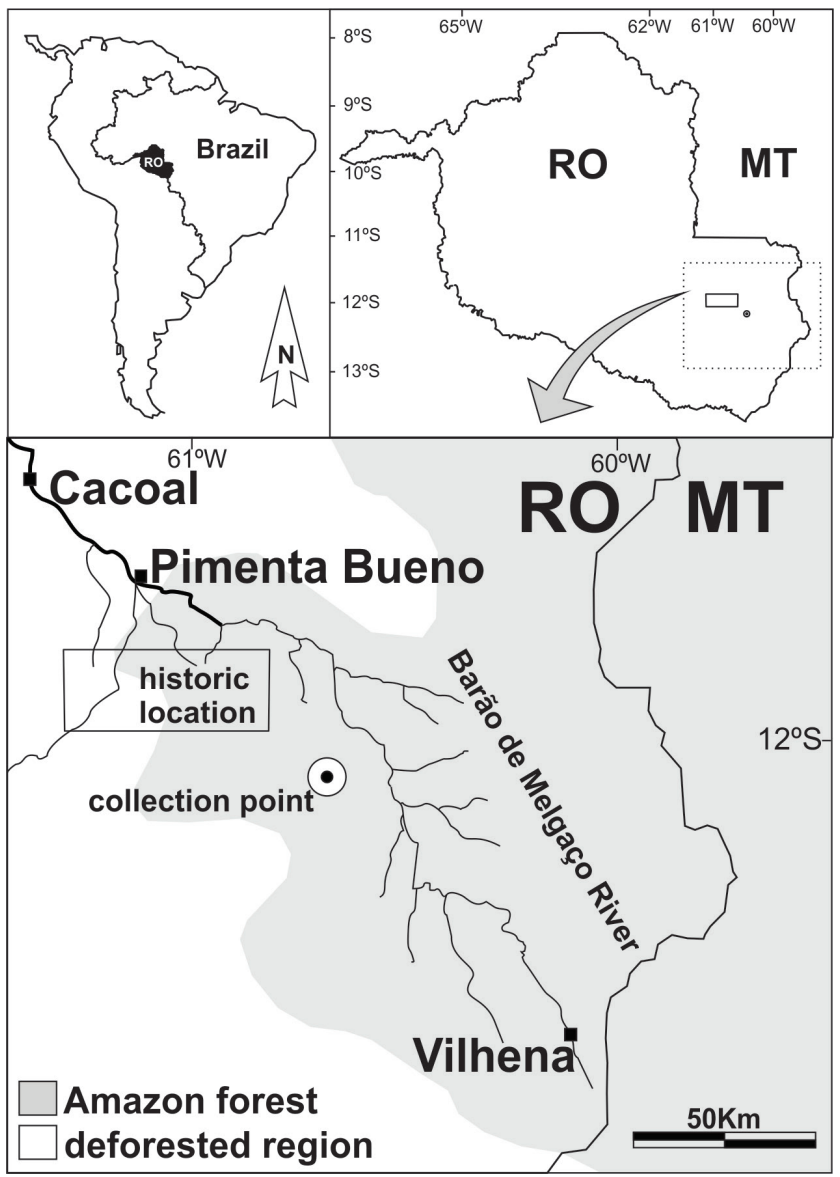

Figure 1. Map showing the locations where Ctenomys bicolor was captured. The rectangle represents the historical limits of the original capture by Miranda-Ribeiro, as defined by Bidau and Avila-Pires (2009). The dot represents the exact point of capture of the present individuals, only $40 \mathrm{~km}$ distant from the southeast corner of the historically defined type locality.

In this study, we report the use of an integrative approach with DNA sequences and geometric morphometrics analysis to evaluate the taxonomic validity of C. bicolor. We also discuss its evolutionary relationship to other species from northwestern Brazil.

\section{MATERIAL AND METHODS}

\section{Collection site and sampling}

We collected 10 specimens (TR1462-1471) along the banks of the Barão de Melgaço River (12 $\left.13^{\prime} 32.41^{\prime \prime S}, 60^{\circ} 40^{\prime} 48.56^{\prime \prime} \mathrm{W}\right)$, in the Pimenta Bueno Municipality, State of Rondônia, near the type locality previously assigned to C. bicolor (Figure 1). We also collected 10 specimens in a nearby area, where $C$. nattereri has been recorded previously. Individuals were 
caught using Oneida Victor traps, under license from the Brazilian government (IBAMA, Authorization No. 14690-1). Standard external measurements (in millimeters) and weight (in grams) were taken by the authors. Tissue samples (liver, kidney, or heart) were collected and stored in $96 \%$ ethanol at $-20^{\circ} \mathrm{C}$ until use.

\section{DNA extraction, amplification, and sequencing}

Total genomic DNA was isolated using the CTAB method (Doyle and Doyle, 1987) from all individuals collected. A partial region of the cytochrome $b$ gene $(820 \mathrm{bp})$ was amplified through the polymerase chain reaction (PCR) using primer pairs MVZ05 and MVZ16 (Smith and Patton, 1993). PCR amplifications were carried out in a reaction volume of 20 $\mu \mathrm{L}$ containing $1 \mathrm{U}$ Taq polymerase (Invitrogen), $20 \mathrm{ng}$ DNA, $0.3 \mu \mathrm{L} 10 \mathrm{mM}$ each primer, 0.3 $\mu \mathrm{L} 10 \mathrm{mM}$ deoxynucleotide triphosphates, $2 \mu \mathrm{L} 10 \mathrm{X}$ buffer, and $1.2 \mu \mathrm{L} 50 \mathrm{mM} \mathrm{MgCl}$. The amplification conditions were 2 min of initial denaturation, 30 cycles of $15 \mathrm{~s}$ of denaturation at $95^{\circ} \mathrm{C}, 30 \mathrm{~s}$ of annealing at $50^{\circ} \mathrm{C}$, and $45 \mathrm{~s}$ of extension at $72^{\circ} \mathrm{C}$, followed by $5 \mathrm{~min}$ of final extension at $72^{\circ} \mathrm{C}$. The PCR products were purified using the enzymes Exonuclease I (GE Healthcare) and shrimp alkaline phosphatase, and sequenced on an ABI 3730XL (Applied Biosystems) DNA analyzer at Macrogen Inc. (Seoul, Republic of Korea). In order to infer the phylogenetic position of C. bicolor, we also used 12 sequences from the Bolivian-Matogrossense and Bolivian-Paraguayan species groups proposed by Contreras and Bidau (1999), and three undescribed forms from Bolivia that were previously sequenced in other studies (Table 1). The outgroup consisted of C. sociabilis and the octodontid Octodon degus.

Table 1. Species used in the molecular approach of this study.

\begin{tabular}{|c|c|c|c|c|}
\hline Phylogenetic group* & Species & Specimen ID & GenBank acession No. & Reference \\
\hline \multicolumn{5}{|l|}{ Ingroup } \\
\hline \multirow[t]{19}{*}{ Bolivian-Matogrossense } & \multirow[t]{10}{*}{ Ctenomys bicolor } & TR1462 & JX880040 & This study \\
\hline & & TR1463 & JX880041 & This study \\
\hline & & TR1464 & JX880042 & This study \\
\hline & & TR1465 & JX880043 & This study \\
\hline & & TR1466 & JX880044 & This study \\
\hline & & TR1467 & JX880045 & This study \\
\hline & & TR1468 & JX880046 & This study \\
\hline & & TR1469 & JX880047 & This study \\
\hline & & TR1470 & JX880048 & This study \\
\hline & & TR1471 & JX880049 & This study \\
\hline & C. boliviensis & NK12438 & AF007040 & Lessa and Cook, 2008 \\
\hline & C. boliviensis 'ROBO’ & NK12437 & AF007039 & Lessa and Cook, 2008 \\
\hline & C. goodfellowi & NK13030 & AF007051 & Lessa and Cook, 2008 \\
\hline & C. nattereri & C-03968 & HM777484 & Parada et al., 2011 \\
\hline & & JFBS2 & JX880036 & This study \\
\hline & & JFBS3 & JX880037 & This study \\
\hline & & JFBS4 & JX880038 & This study \\
\hline & & JFBS5 & JX880039 & This study \\
\hline & C. steinbachi & NK12134 & AF007044 & Lessa and Cook, 2008 \\
\hline \multirow[t]{3}{*}{ Bolivian-Paraguayan } & C. conoveri & NK12607 & AF007055 & Lessa and Cook, 2008 \\
\hline & C. frater & NK14622 & AF007046 & Lessa and Cook, 2008 \\
\hline & C. lewesi & NK14649 & AF007049 & Lessa and Cook, 2008 \\
\hline \multirow[t]{3}{*}{ No group assigned } & Ctenomys sp. 'ITA' & NK12221 & AF007047 & Lessa and Cook, 2008 \\
\hline & Ctenomys sp. 'MINUT' & NK12406 & AF007052 & Lessa and Cook, 2008 \\
\hline & Ctenomys sp. 'MONTE' & NK12404 & AF007053 & Lessa and Cook, 2008 \\
\hline \multicolumn{5}{|l|}{ Outgroup } \\
\hline No group assigned & C. sociabilis & EAL 545 & HM777495 & Parada et al., 2011 \\
\hline- & Octodon degus & NK17520 & AF007059 & Lessa and Cook, 2008 \\
\hline
\end{tabular}

*Based on Contreras and Bidau (1999). 


\section{Phylogenetic analysis}

Sequences were aligned and visually inspected using the algorithm ClustalX in MEGA 5 (Tamura et al., 2011) running in full mode with no manual adjustment. Uncorrected genetic distances ( $p$-distance) with pairwise deletion were computed between species, using MEGA.

Bayesian inference was implemented in BEAST 1.6.1 (Drummond and Rambaut, 2007 ) to recover the phylogenetic relationships and simultaneously obtain an estimate of the divergence time for the lineages of tuco-tucos surveyed in this study. The HKY85i model of sequence evolution (Hasegawa et al., 1985) was used with empirical base frequencies and four gamma categories. A relaxed uncorrelated log-normal clock was used, together with no fixed mean substitution rate. This method incorporates the time-dependent nature of the evolutionary process without assuming a strict molecular clock. We used a Yule prior on branching rates, as our focus was a species-level phylogeny. Additionally, one prior was specified in the form of a calibration point as the time of the most recent common ancestor (tMRCA) for Caviomorpha (28.5 to 37 mya; Wyss et al., 1993). Four independent runs of 10 million generations were implemented, with the first 500,000 generations of each run discarded as burn-in. Posterior probabilities were used as an estimate of branch support.

\section{Karyotype analysis}

Two male and two female individuals were karyotyped, following the procedure of Baker et al. (1982). Mitotic metaphases from bone marrow were stained using phosphatebuffered Giemsa stain to determine the diploid n (2n) and fundamental numbers (FN). A total of 10 metaphases per animal were evaluated. The terminology for chromosome morphology follows Patton (1967).

\section{Geometric morphometric analysis}

In order to determine the classification of our 10 specimens collected, skulls from two museum specimens, including the single specimen from the historic type locality [MNRJ-2052 (holotype) and AMNH-37121] were also incorporated into the data set. Specimen AMNH-37121 is currently designated as $C$. nattereri, but we presumed that this was a misidentification because its collection site (José Bonifácio Municipality, Rondônia State) overlaps that of C. bicolor. Our hypothesis that this sample represents a specimen of C. bicolor was tested in this study. Additionally, these 13 specimens were compared with 64 samples representative of the BolivianMatogrossense group: $C$. boliviensis $(\mathrm{N}=52)$ and $C$. steinbachi $(\mathrm{N}=12)$. A single skull from a specimen of C. boliviensis from Robore, Bolivia (FMNH-28358), considered a distinct lineage based on previous studies (Lessa and Cook, 1998), was also used for descriptive comparisons with $C$. bicolor. The individuals analyzed are described in the Supplementary material.

The geometric morphometrics of the cranium shape was captured by a configuration of topographically corresponding landmarks modified from D'Anatro and Lessa (2006). Each cranium was photographed in dorsal, ventral, and lateral views, using a digital camera with 3.1 megapixels (2048 x 1536) of resolution, macro function, and without zoom or flash. We used 15 two-dimensional landmarks for dorsal, 13 for ventral, and 12 for lateral views of the skull (Table 2). For dorsal and ventral representations, skulls were digitized only on the left 
side to avoid including redundant information in symmetrical structures, according to Cardini and O'Higgins (2004). The anatomical landmarks were digitized by the same individual for each specimen, using TPSDig2 2.16 (http://life.bio.sunysb.edu/morph). Coordinates were superimposed using a generalized Procrustes analysis (GPA) algorithm (Dryden and Mardia, 1998). GPA removes differences unrelated to shape, such as scale, position, and orientation (Rohlf and Slice, 1990). The error in landmark acquisition (operator variance) was evaluated through a one-way analysis of variance (ANOVA) of centroid size for the repeated landmark acquisition of one image for each species. The mean estimated measurement error was $0.08 \%$. The size of each skull was estimated using its centroid size; namely, the square root of the sum of the squares of the distance of each landmark from the centroid (mean of all coordinates) of the configuration (Bookstein, 1991). Because each skull had three separate centroid sizes for each view, we calculated a single value by summing the logarithms of the dorsal, ventral, and lateral centroid sizes. We also used form (size + shape), using log-transformed centroid size plus the principal components matrix of shape variables. Differences in the shape of the skull inferred from statistical analyses were visualized through multivariate regression of shape variables on discriminant axes.

Table 2. Characterization of 40 two-dimensional landmark views of the skull used in this study.

\begin{tabular}{|c|c|c|}
\hline View position & ID & Description \\
\hline \multirow[t]{15}{*}{ Dorsal } & 1 & Anterior extremity of suture between nasals \\
\hline & 2 & Anterolateral extremity of incisor alveolus \\
\hline & 3 & Anteriormost point of root of zygomatic arch \\
\hline & 4 & Externalmost point of orbit in zygomatic arch foramen \\
\hline & 5 & Suture between nasals and frontals \\
\hline & 6 & Tip of extremity of superior jugal process \\
\hline & 7 & Lateral extremity of suture between jugal and squamosal in the zygomatic arch \\
\hline & 8 & Suture between squamosal and jugal \\
\hline & 9 & Suture between frontals and parietals \\
\hline & 10 & Suture between frontal, parietal, and squamosal \\
\hline & 11 & Tip of posterior process of jugal \\
\hline & 12 & Internalmost contact between squamosal and tympanic bulla \\
\hline & 13 & Anterior tip of external auditory meatus \\
\hline & 14 & Point of maximum curvature on mastoid apophysis \\
\hline & 15 & Posteriormost point of occipital along the midsagittal plane \\
\hline \multicolumn{3}{|r|}{$\mathrm{C}$} \\
\hline & 1 & Anterior extremity of suture between premaxillaries \\
\hline & 2 & Anterolateral extremity of incisive alveolus \\
\hline & 3 & Suture between premaxillary and maxillary in the external outline of the skull \\
\hline & 4 & Tip of suture between premaxillaries in the incisive foramen \\
\hline & 5 & Externalmost point of orbit in zygomatic arch foramen \\
\hline & 6 & Anteriormost point of first molar alveolus \\
\hline & 7 & Anteriormost point of intersection between jugal and squamosal \\
\hline & 8 & Posteriormost point of fourth molar alveolus \\
\hline & 9 & Anteriormost point in mesopterygoid fossa \\
\hline & 10 & Anterior extremity of tympanic bulla \\
\hline & 11 & Internalmost contact between squamosal and tympanic bulla \\
\hline & 12 & Posterior extremity of mastoid apophysis \\
\hline & 13 & Posteriormost point of foramen magnum along midsagittal plane \\
\hline \multicolumn{3}{|r|}{. } \\
\hline & 1 & Point of intersection between premaxillary and posterior end of incisor \\
\hline & 2 & Anteriormost point of suture between nasals and premaxillary \\
\hline & 3 & Anterior extremity of suture between nasals \\
\hline & 4 & Suture between premaxillary, maxillary, and frontal in superior zygomatic root \\
\hline & 5 & Suture between premaxillary and maxillary in the outline of the skull (at the photographic plane) \\
\hline & 6 & Anteriormost point of premolar alveolus \\
\hline & 7 & Inferior end of suture between maxillary and jugal in zygomatic arch \\
\hline & 8 & Extremity of superior jugal process \\
\hline & 9 & Tip of posterior jugal process \\
\hline & 10 & Extremity of inferior jugal process \\
\hline & 11 & Superior extremity of lambdoidal crest \\
\hline & 12 & Anteriormost margin of paraoccipital apophysis \\
\hline
\end{tabular}


Differences in the log of centroid size of taxa or populations were tested with ANOVA and the Student $t$-test and pairwise comparisons using Bonferroni tests. Differences in shape were explored by canonical variate analyses (CVA) and multivariate ANOVA. To visualize the shape differences, deformations along factorial axes were calculated by multivariate regressions. To test the validity of the a priori taxonomic assignments, classification percentages were estimated by multiple discriminant functions, using shape and form (size + shape) parameters and leave-one-out cross-validations. Because of the relatively small sample sizes and the large number of variables (40 bidimensional landmarks), statistical analyses of shape were performed using the dimension-reduction approach proposed by Baylac and Friess (2005): we used the smallest first PC set that maximizes the discrimination values. All morphometric calculations were performed using the R language, version 2.0 for Linux (R Development Core Team, 2004). Morphometric procedures were carried out with the "Rmorph" library for R (Baylac, 2007).

\section{RESULTS}

The body measurements of the 10 specimens collected in the type locality of $C$. bicolor fall within the range of variation reported by Miranda Ribeiro (1914) for the type species, as follows: total length $=403 \pm 23 \mathrm{~mm}$, body length $=314 \pm 17 \mathrm{~mm}$, hind foot with nail $=45 \pm$ $1.8 \mathrm{~mm}$, hind foot without nail $=39.9 \pm 1.27 \mathrm{~mm}$, and mass $=418 \pm 100 \mathrm{~g}$.

\section{DNA sequence variation}

Complete sequences (1140 bp) of cytochrome $b$ from 17 individuals analyzed together with 10 partial sequences (820 bp) of C. bicolor resulted in 377 (32\%) variable sites. Specifically, in $C$. bicolor we found three haplotypes, a haplotype diversity of $0.37 \pm 0.18$, and a nucleotide diversity of $0.001 \pm 0.0006$.

\section{Phylogenetic relationships and node age estimates}

The phylogenetic reconstruction showed that $C$. bicolor is monophyletic with high posterior probability node support, and is related to the Bolivian-Matogrossense group (Figure 2). This group is a well-supported monophyletic clade that includes C. boliviensis, C. goodfellowi, and C. nattereri, as proposed by Contreras and Bidau (1999), and Ctenomys sp. from Robore, Bolivia (Lessa and Cook, 1998). In addition, the three undetermined Bolivian forms (ITA, MONTE, and MINUT) form a clade that might be included in the Bolivian-Matogrossense group, although with low node support. C. steinbachi is a poorly supported sister to this group. Interspecific divergence between $C$. bicolor and other species of Ctenomys ranged from $0.03 \pm 0.01$ (C. boliviensis) to $0.11 \pm 0.01$ (C. sociabilis) (Table 3). The estimates of divergence dates had broad confidence intervals (Figure 2, Table 4). The tMRCA of Ctenomys was dated at 8.2 mya (7.4 to 12.2 mya). Most of the tMRCA for species groups were dated to around 3 mya (Figure 2).

\section{Karyotype}

The karyotype observed in specimens collected in Pimenta Bueno was $2 n=40$ and 
$\mathrm{FN}=68$ (Figure 3). The chromosomal complement consists of five pairs of submetacentrics, from medium to large; six pairs of metacentrics, from small to large; and eight pairs of acrocentrics, from small to large. The $\mathrm{X}$ chromosome was observed as a large metacentric (Figure 3).

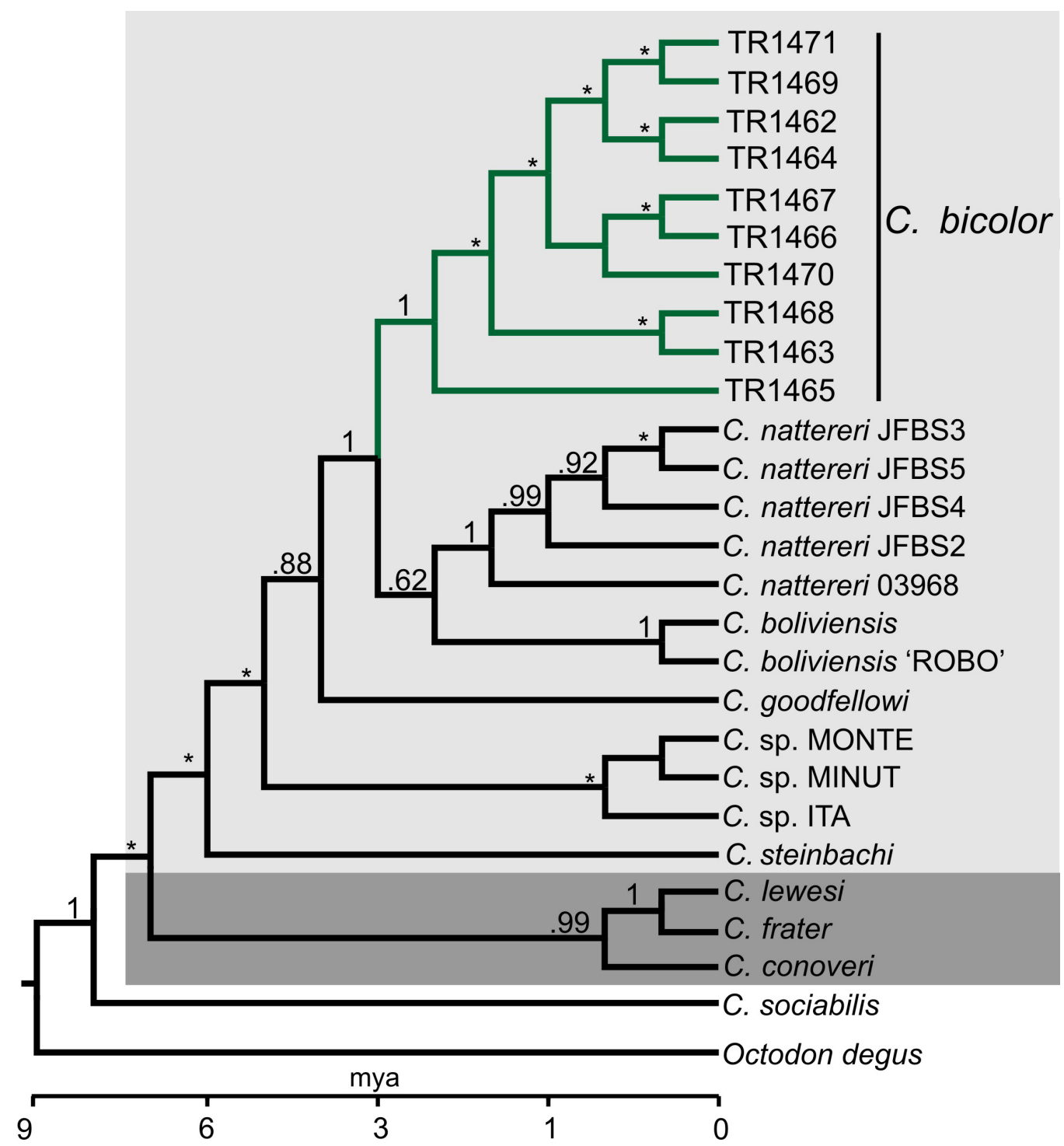

Figure 2. Bayesian cladogram representing phylogenetic relationships for 9 nominal species and 4 morphotypes of Ctenomys based on sequences of the cytochrome-b gene. Numbers above branches are posterior probability support. The Ctenomys bicolor monophyletic clade is represented by green branches. Asterisks indicate branch support $<60 \%$. Clades depicted in light and dark gray are the Bolivian-matogrossense and Bolivian-Paraguayan phylogenetic groups, respectively. 
Table 3. Uncorrected p-distance estimates between pairs of species of Ctenomys. Shaded column shows comparisons between Ctenomys bicolor and all other species.

\begin{tabular}{|c|c|c|c|c|c|c|c|c|c|c|c|c|}
\hline & 1 & 2 & 3 & 4 & 5 & 6 & 7 & 8 & 9 & 10 & 11 & 12 \\
\hline \multicolumn{13}{|l|}{ 1. C. bicolor } \\
\hline 2. C. boliviensis & 0.03 & & & & & & & & & & & \\
\hline 3. C. boliviensis ' $\mathrm{ROBO}$ ' & 0.03 & 0.00 & & & & & & & & & & \\
\hline 4. C. conoveri & 0.10 & 0.10 & 0.10 & & & & & & & & & \\
\hline 5. C. frater & 0.11 & 0.10 & 0.10 & 0.08 & & & & & & & & \\
\hline 6. C. goodfellowi & 0.07 & 0.06 & 0.06 & 0.09 & 0.09 & & & & & & & \\
\hline 7. Ctenomys sp. 'ITA' & 0.08 & 0.07 & 0.07 & 0.09 & 0.09 & 0.06 & & & & & & \\
\hline 8. C. lewensi & 0.10 & 0.09 & 0.09 & 0.07 & 0.04 & 0.09 & 0.09 & & & & & \\
\hline 9. Ctenomys sp. 'MINUT' & 0.08 & 0.07 & 0.07 & 0.09 & 0.09 & 0.06 & 0.05 & 0.09 & & & & \\
\hline 10. Ctenomys sp. 'MONTE' & 0.08 & 0.07 & 0.07 & 0.08 & 0.09 & 0.06 & 0.05 & 0.09 & 0.00 & & & \\
\hline 11. C. nattereri & 0.04 & 0.02 & 0.02 & 0.10 & 0.10 & 0.06 & 0.07 & 0.10 & 0.06 & 0.06 & & \\
\hline 12. C. sociabilis & 0.11 & 0.10 & 0.10 & 0.11 & 0.12 & 0.12 & 0.11 & 0.12 & 0.12 & 0.12 & 0.10 & \\
\hline 13. C. steinbachi & 0.08 & 0.07 & 0.07 & 0.09 & 0.09 & 0.06 & 0.06 & 0.09 & 0.07 & 0.07 & 0.07 & 0.10 \\
\hline
\end{tabular}

Table 4. Divergence times recovered as mean estimates between some lineages of Ctenomys. Each value represents the estimated divergence time (mya) and 95\% confidence interval. Lineages are indicated in Figure 2.

\begin{tabular}{lc}
\hline Lineage & Divergence time \\
\hline tMRCA Ctenomys & $6.7(4.2-10.7)$ \\
All Ctenomys but C. sociabilis & $4.2(3.3-9.2)$ \\
Bolivian-Paraguayan & $3.56(2.8-6.7)$ \\
Bolivian-Matogrossense & $2.68(1.9-4.3)$ \\
\hline
\end{tabular}

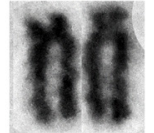

1

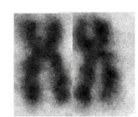

8

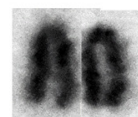

14

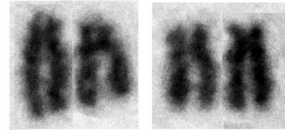

2

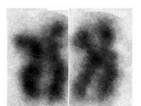

9

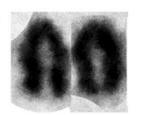

15
3

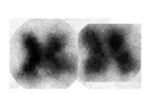

10

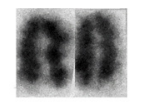

16

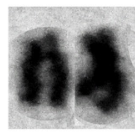

4

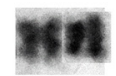

11

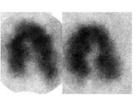

17

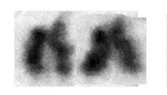

5

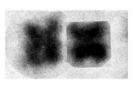

12

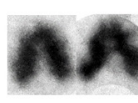

18

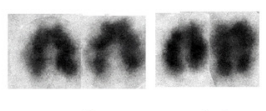

6

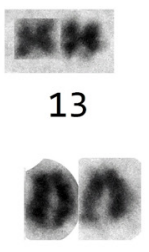

19

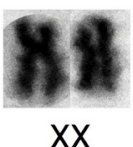

$2 n=40$

Figure 3. Ctenomys bicolor female karyotype, showing the chromosome arms. $2 \mathrm{n}=40$ and $\mathrm{FN}=64$.

\section{Geometric morphometrics}

Geometric morphometrics analysis of the skull revealed significant differences in centroid size between the species for the dorsal (ANOVA: $\mathrm{P}<0.001 ; \mathrm{F}=17.28$ ), lateral (ANOVA: $\mathrm{P}<0.001 ; \mathrm{F}=27.24$ ), and ventral views (ANOVA: $\mathrm{P}<0.001 ; \mathrm{F}=29.09$ ). Tukey pairwise comparison showed significant differences in size between $C$. bicolor and C. boliviensis $(\mathrm{P}<$ $0.001)$ and between $C$. bicolor and C. steinbachi $(\mathrm{P}<0.001)$, but not between C. boliviensis 
and $C$. steinbachi $(\mathrm{P}=0.974)$. The results of the MANOVA showed significant differences in shape for all skull views, both separately and pooled together $(\mathrm{P}<0.01$; dorsal: Wilks $=0.38$, $\mathrm{F}=22.29$; lateral: Wilks $=0.43, \mathrm{~F}=19.08$; ventral: Wilks $=0.08, \mathrm{~F}=9.32$; and the three views pooled: Wilks $=0.36, \mathrm{~F}=10.35$ ). The percentage of correct classification using form (size + shape) provided the highest value (100\%) for the three species analyzed, for the three views of the skull separately and pooled together (Table 5), with the exception of the lateral view of $C$. boliviensis, reaching $92.3 \%$ of correct reclassification, and included the correct reclassification of AMNH-37121 as C. bicolor.

Table 5. Percentage of correct classification from the linear discriminant analysis for previously recognized species of Ctenomys for dorsal, lateral, ventral, and the three views pooled of the skull, using form (size + shape).

\begin{tabular}{lccc}
\hline View & C. bicolor & C. boliviensis & C. steinbachi \\
\hline Dorsal & 100 & 100 & 100 \\
Lateral & 92.3 & 100 & 100 \\
Ventral & 100 & 100 & 100 \\
All & 100 & 100 & 100 \\
\hline
\end{tabular}

The CVA results from the three views combined with Mahalanobis distances showed a clear separation in form among the three species analyzed, indicating that $C$. bicolor is more distinct in form among these species than $C$. boliviensis and $C$. steinbachi are from each other (Figure 4). Specimen AMNH-37121 falls within the variation reported for C. bicolor, as presumed from its collection locality. The shape differences among species are shown in Figure 5.

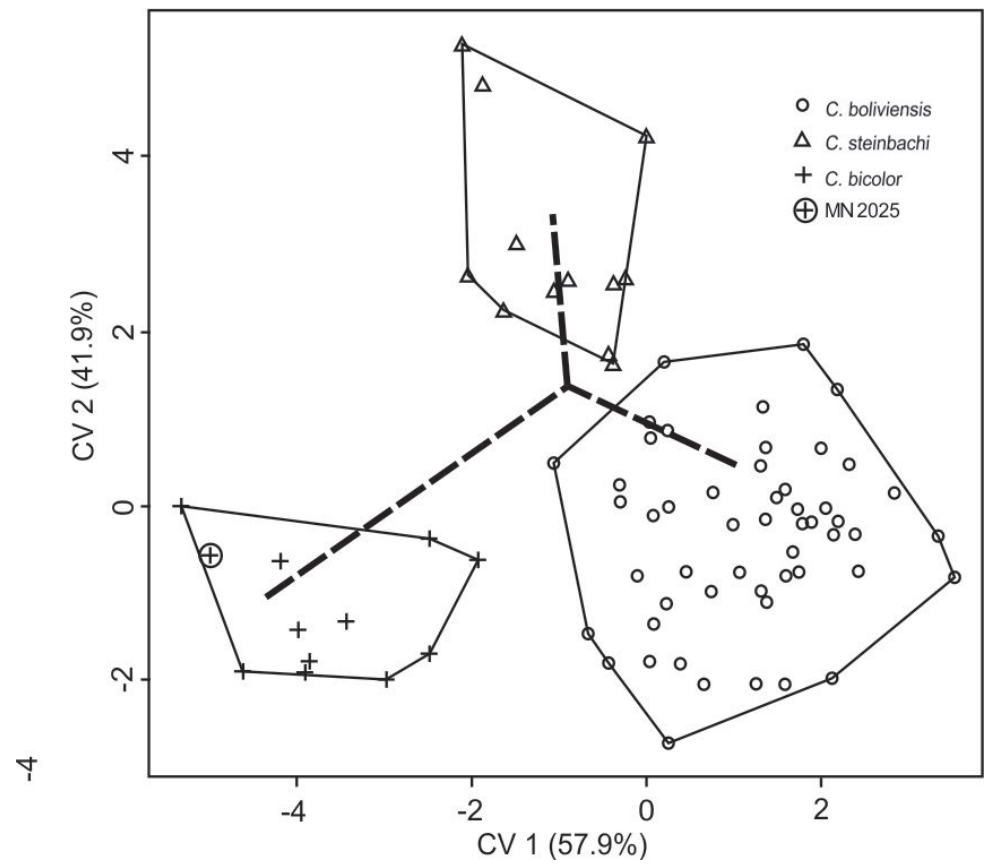

Figure 4. Canonical variate analysis of Ctenomys species form (shape) variables using three cranial views combined. The dotted line represents the Mahalanobis distance for the three species analyzed. 


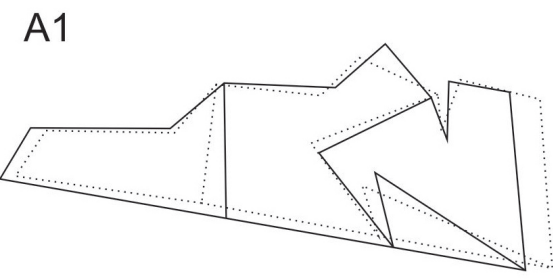

B1

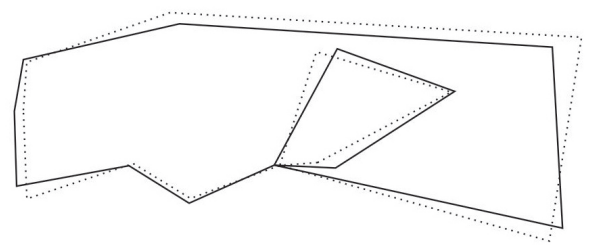

C1

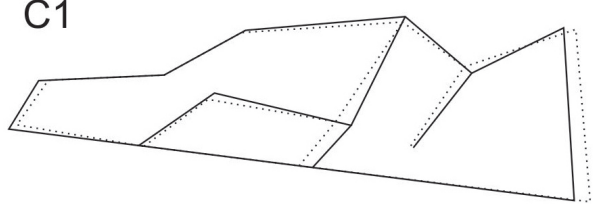

\section{$\mathrm{A} 2$}

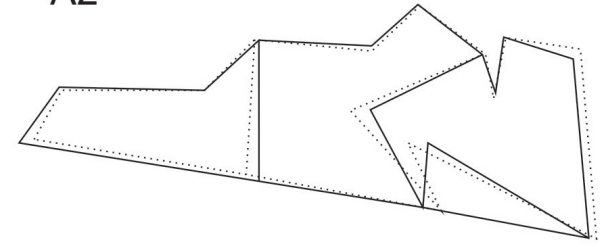

B2
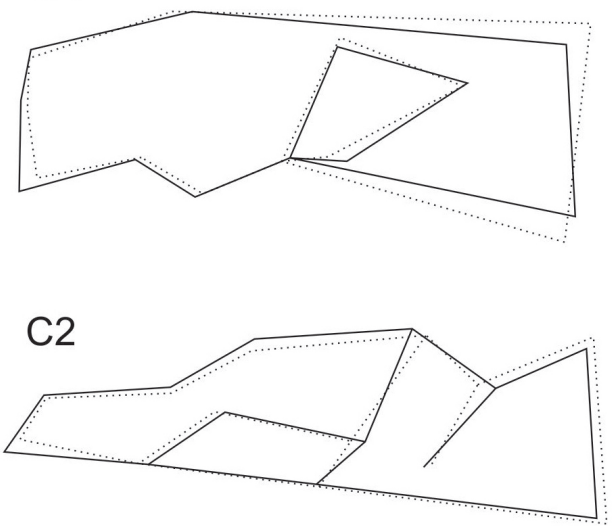

Figure 5. Skull shape differences for three Ctenomys species (C. boliviensis, C. bicolor, and C. steinbachi), for dorsal (A), lateral (B), and ventral (C) views of the skull. Positive PC scores (solid lines), negative PC scores (dotted lines), PC1 (1), PC2 (2).

\section{Cranial description and linear measurements}

The frontal bones have a triangular lateral expansion, with the outer point of the triangle directed toward the front of the cranium (Figure 6). The rostrum is short and narrow. The nasal ends at the line of insertion of the zygomatic arch. The skull is large and rounded. The zygomatic arch is slightly narrower than the width of the auditory meatus, rounded, and narrows in the anterior half. The parietal and frontal are long, and the nose is proportionately short. Laterally, the skull is somewhat flattened, with a very robust braincase and well-developed tympanic bulla, the diastema slightly spaced, and the incisors slightly procumbent. The molar series is short. The auditory bullae are large, long, and robust. The frontals have a triangular protuberance on the lateral side, with the outer edge of the triangle directed toward the front of the skull, which distinguishes it from other ctenomyids (Figure 6). Linear cranial measurements, in millimeters, were as follows: greatest skull length $=48.76$; nasal $=16.66$; rostral $=18.77$; orbital $=14.77$; rostral breadth $=12.86$; interorbital constriction $=13.05$; mastoid breadth $=33.19$; zygomatic breadth $=32.97$; condyloincisive $=49.76$; basilar $=42.46$; diastema $=13.37$; maxillary toothrow $=10$; palatal $\mathrm{a}=23.02$; palatal $\mathrm{b}=8.76$; incisive foramina $=7.89$; bullar $=$ 14.45 ; post palatal $=18.68$; mesopterygoid fossa width $=6.17$; maxillary breadth $=10.15$; occipital condyle width $=9.9$; rostral depth $=10.22$; cranial depth $=19.62$; cranial depth at $\mathrm{m} 1=17.92$. 
A

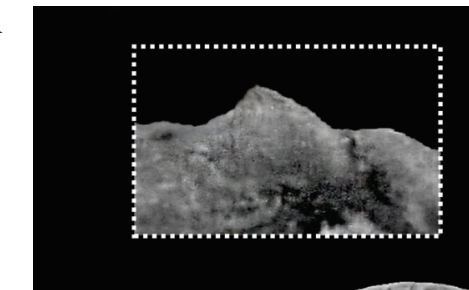

B

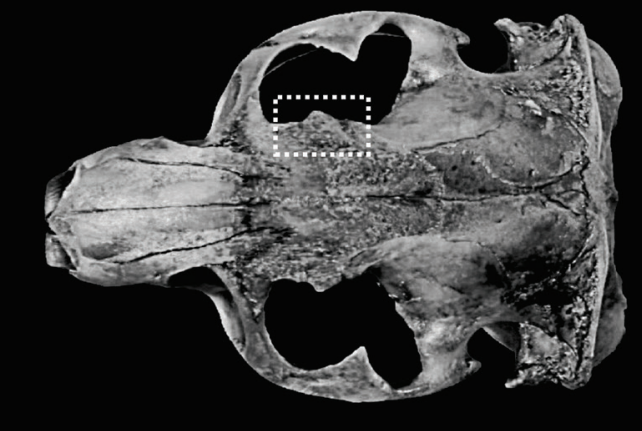

C

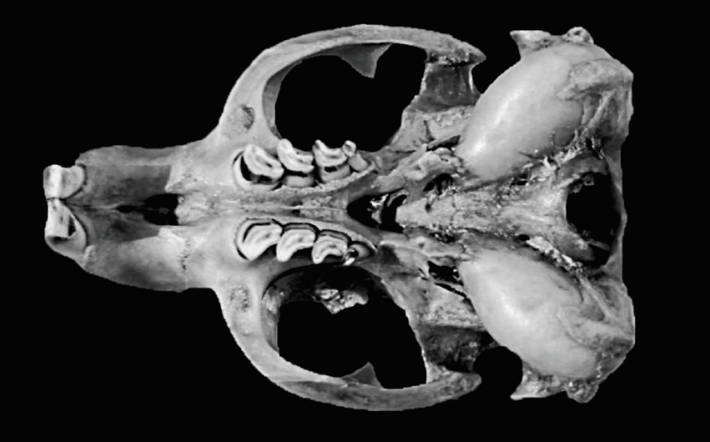

D

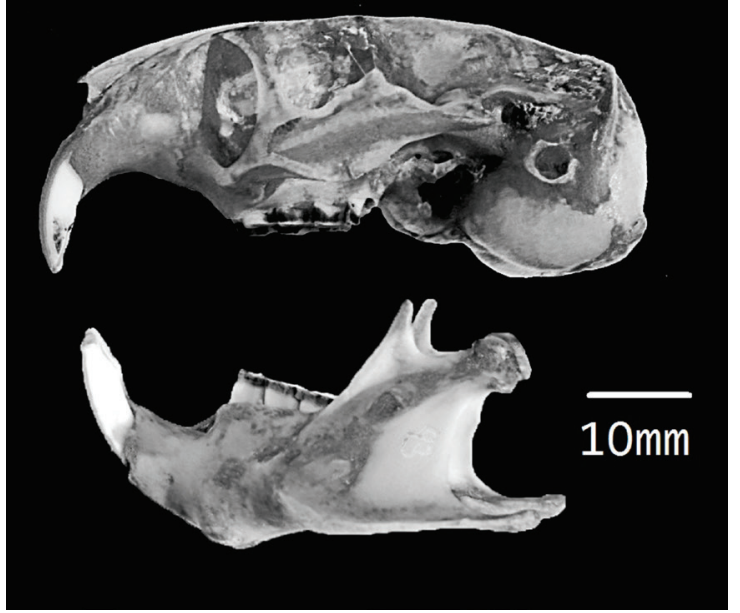

Figure 6. Ctenomys bicolor skull. A. detail of the diagnostic triangular lateral expansion of the frontal bone, with the outer edge pointing toward the front of the skull; B. dorsal, C. ventral, D. and lateral views, showing the mandible. 
Integrative analysis of C. bicolor

\section{DISCUSSION}

DNA-based analysis and chromosomal data showed that the specimens collected in the State of Rondônia represent $C$. bicolor.

C. bicolor is genetically distinct from all other species of Ctenomys that occur nearby in the Bolivian region, as well as in the State of Mato Grosso in Brazil. Sequence divergence was compared within the Bolivian-Matogrossense and Bolivian-Paraguayan groups, and the most similar species (C. boliviensis) showed 3\% divergence, which is high for this genus (Parada et al., 2011).

Similarly, morphological analysis supports the recognition of a valid species. The identification of the original material deposited in the museum collection was doubtful, as different collection numbers can be found in various studies (Miranda Ribeiro, 1955; Langguth et al., 1997), and a collection number was not provided in the original description. This situation raised the question of the correct designation of the material, which was one of the goals of this study. Moreover, the original description of the species did not allow accurate recognition, since it was based on skull and external characters that fit the descriptions of other ctenomyids. C. bicolor was not recognized in the latest taxonomic revision (Wilson and Reeder, 2005) and has not been cited as a species or included in any study in the almost 100 years that have passed since its description. This history led us to question the status of the species.

The present analysis confirmed important differences for specimens from Pimenta Bueno, and with new information about the historical collection point, we assume that our specimens are C. bicolor. Although the deposited specimen (MNRJ-2052) is damaged, the skull analysis placed the museum specimen within this population, reinforcing the presumption that it belongs to the same species.

The tMRCA of Ctenomys was estimated at 8.2 mya, a value older than previous estimates (3.7 mya; Castillo et al., 2005) or the evidence from the fossil record, which suggests that the split between Ctenomyidae and Octodontidae occurred not more than 9 mya (Verzi 2002; Verzi et al., 2010).

\section{C. bicolor morphological differences}

The skull resembles $C$. minutus, from which it is separated by the greater width of the diameter over the zygomatic arches. It is more strongly curved and larger; the post-eye process on the frontal is lacking in C. minutus; the parietal and palatine are narrower, for which the outline of the front can be defined by a hexagon; and the molars are weaker. It differs from C. rondoni in the shape of the occipital foramen, which lacks upper transverse processes; the wider frontal and interparietal; and the curvature of the zygomatic arches, which have the anterior border arched and not square.

In comparison with $C$. boliviensis from Robore (FMNH-28358), the species from which it diverges least, the zygomatic arch is more rounded in the skull, larger than the meatus width, with a proportionally longer rostrum; and it lacks the triangular lateral expansion of the frontal bone, but rather has an adorned quadrate structure that clearly does not fit within the diagnosis of C. bicolor.

Originally, no type series was associated with $C$. bicolor in the MNRJ, except the holotype. Thus, our study significantly improved the museum collection data by providing a series of specimens for C. bicolor, which can be used for comparisons in future studies. 


\section{Habitat and conservation of $C$. bicolor}

C. bicolor is restricted to small areas in sandy-soil portions of the southern Amazon basin. The collection site of this species is located in the middle of the Amazon Forest, near the city of Pimenta Bueno and the Barão do Melgaço River, where Rondon's expedition crossed during his journey through western Brazil, according to Bidau and Avila-Pires (2009). The historical reference suggests that this species occurs along the sandy banks of the Barão de Melgaço River. In this study, we searched for any existing evidence regarding the presence of tuco-tucos in the surrounding area, and observed that they are sparsely distributed in the forest where the soil is sandier. The nearest known record of another species of Ctenomys is located at a distance of $350 \mathrm{~km}$, in the Pontes e Lacerda Municipality in the State of Mato Grosso. Although we sampled extensively in the area between these populations, we found no evidence of the presence of tuco-tucos.

C. bicolor occurs in Rondônia, where human impacts in forest areas have been particularly intense. The animals usually occur inside the forest as well as along its borders. However, they are currently also found in areas completely modified by many kinds of crops. Thus, a broader knowledge about the geographic distribution, genetics, and ecological status of this species will contribute significantly to its conservation.

\section{ACKNOWLEDGMENTS}

Research supported by Coordenadoria de Aperfeiçoamento Pessoal, Conselho Nacional de Desenvolvimento Científico e Tecnológico, and Fundação de Amparo à Pesquisa do Rio Grande do Sul. J.F.B. Stolz and G.L. Golçalves received a doctoral fellowship from Conselho Nacional de Desenvolvimento Científico e Tecnológico.

\section{Supplementary material}

\section{REFERENCES}

Allen JA (1916). Mammals collected on the Roosevelt Brazilian Expedition with field notes by Leo L. Miller. Bull. Am. Mus. Nat. Hist. 35: 559-610.

Avila-Pires FD (1968). Tipos de mamíferos recentes no Museu Nacional, Rio de Janeiro. Arch. Mus. Nac. 53: 161-191.

Baker RJ, Haiduk MW, Robbins LW, Cadena A, et al. (1982). Chromosomal Studies of South American Bats and their Systematic Implications. In: Mammalian Biology in South America. (Mares MA and Genoways HH, eds.). Special Publication, Pymatuning Laboratory of Ecology, University of Pittsburgh, Pittsburgh, 1-539.

Baylac M and Friess M (2005). Fourier Descriptors, Procrustes Superimposition and Data Dimensionality: an Example of Cranial Shape Analysis in Modern Human Populations. In: Modern Morphometrics in Physical Anthropology. (Slice DE, ed.). Springer-Verlag, New York, 145-166.

Baylac M (2007). Rmorph: a R geometric and multivariate morphometrics library. Available from the author: baylac@ mnhn.fr.

Bidau CJ and Avila-Pires FD (2009). On the type locality of Ctenomys bicolor Miranda-Ribeiro, 1914 (Rodentia: Ctenomyidae). Mast. Neotrop. 16: 445-447.

Bookstein FL (1991). Morphometric Tools for Landmark Data: Geometry and Biology. Cambridge University Press, London.

Cardini A and O'Higgins P (2004). Patterns of morphological evolution in marmota (Rodentia, Sciuridae): geometric morphometrics of the cranium in the context of marmot phylogeny, ecology and conservation. Biol. J. Linn. Soc. 82: $385-407$. 
Castillo AH, Cortinas MN and Lessa EP (2005). Rapid diversification of South American tuco-tucos (Ctenomys; Rodentia, Ctenomyidae): contrasting mitochondrial and nuclear intron sequences. J. Mamm. 86: 170-179.

Contreras JR and Bidau CJ (1999). Líneas generales del panorama evolutivo de los roedores excavadores sudamericanos del genero Ctenomys (Mammalia, Rodentia, Caviomorpha, Ctenomyidae). Cien. Sig. 1: 1-22.

Cook JA and Lessa EP (1998). Are rates of diversification in subterranean South American tuco-tucos (genus Ctenomys, Rodentia: Octodontidae) unusually high? Evolution 52: 1521-1527.

D'Anatro A and Lessa EP (2006). Geometric morphometric analysis of geographic variation in the Rio Negro tuco-tuco, Ctenomys rionegrensis (Rodentia: Ctenomyidae). Mamm. Biol. 71: 288-298.

Doyle JJ and Doyle JL (1987). A rapid DNA isolation procedure for small quantities of fresh leaf tissue. Phytochem. Bull. 19: 11-15

Drummond AJ and Rambaut A (2007). BEAST: Bayesian evolutionary analysis by sampling trees. BMC Evol. Biol. 7: 214 .

Dryden IL and Mardia KV (1998). Statistical Shape Analysis. John Wiley \& Sons, New York.

Hasegawa M, Kishino H and Yano T (1985). Dating of the human-ape splitting by a molecular clock of mitochondrial DNA. J. Mol. Evol. 22: 160-174.

Langguth A, Limeira VLAG and Franco S (1997). Tipos de mamíferos recentes no Museu Nacional, Rio de Janeiro. Publcoes avuls. Mus. Nac. 70: 1-29.

Lessa EP and Cook JA (1998). The molecular phylogenetics of tuco-tucos (genus Ctenomys, Rodentia: Octodontidae) suggests an early burst of speciation. Mol. Phylogenet. Evol. 9: 88-99.

Miranda Ribeiro ADE (1914). Zoologia. Commisão de Linhas Telegráphicas Estratégicas de Matto-Grosso ao Amazonas. Anexo 5, Historia Natural; 17 Mammíferos. 49.

Miranda Ribeiro P (1955). Tipos das espécies do Prof. Alípio de Miranda Ribeiro depositados no Museu Nacional (Com uma relação dos gêneros, espécies e subespécies descritos). Arq. Mus. Nac. Rio de Janeiro 42: 389-417.

Parada A, D’Elía G, Bidau CJ and Lessa EP (2011). Species groups and evolutionary diversification of tuco-tucos, genus Ctenomys (Rodentia: Ctenomyidae). J. Mamm. 92: 671-682.

Patton JL (1967). Chromosome studies of certain pocket mice, genus Perognathus (Rodentia: Heteromyidae). J. Mammal. 48: 27-37.

R Development Core Team (2009) R: A Language and Environment for Statistical Computing. Vienna: R Foundation for Statistical Computing. Available at [http://www.r-project.org]. Accessed April 29, 2012.

Reig OA, Busch C, Ortells MO and Contreras JR (1990). An Overview of Evolution, Systematics, Population,Biology, Cytogenetics, Molecular Biology and Speciation in Ctenomys. In: Evolution of Subterranean Mammals at the Organismal and Molecular Levels (Nevo E and Reig OA, eds.). Alan R. Liss, New York.

Rohlf JF and Slice D (1990). Extensions of the procrustes method for the optimal superimposition of landmarks. Syst. Zool. 39: 40-59.

Ross KG, Gotzek D, Ascunce MS and Shoemaker DD (2010). Species delimitation: a case study in a problematic ant taxon. Syst. Biol. 59: 162-184.

Smith MF and Patton JL (1993). The diversification of South American murid rodents: evidence from mitochondrial DNA sequence data for the akodontine tribe. Biol. J. Linn. Soc. 50: 149-177.

Tamura K, Peterson D, Peterson N, Stecher G, et al. (2011). MEGA5: molecular evolutionary genetics analysis using maximum likelihood, evolutionary distance, and maximum parsimony methods. Mol. Biol. Evol. 28: 2731-2739.

Verzi DH (2002). Patrones de evolución morfológica en Ctenomyinae (Rodentia: Octodontidae). Mast. Neotrop. 9: 309-328.

Verzi DH, Olivares AI and Morgan CC (2010). The oldest South American tuco-tuco (Late Pliocene, northwestern Argentina) and the boundaries of the genus Ctenomys (Rodentia, Ctenomyidae). Mamm. Biol. 75: 243-252.

Wilson DE and Reeder DM (2005). Mammal Species of the World. A Taxonomic and Geographic Reference. Johns Hopkins University Press, Baltimore.

Woods CA and Kilpatrick CW (2005). Hystricognathi. In: Mammal Species of the World. A Taxonomic and Geographic Reference (Wilson DE and Reeder DM, eds.). Johns Hopkins University Press, Baltimore.

Wyss A, Flynn J, Norell M, Swisher C, et al. (1993). South America's earliest rodent and recognition of a new interval of mammalian evolution. Nature 365: 434-437. 